\title{
Randomized, Multicenter, Warfarin-Controlled Phase II Study of Edoxaban in Japanese Patients With Non-Valvular Atrial Fibrillation
}

\author{
Takeshi Yamashita, MD; Yukihiro Koretsune, MD; Masahiro Yasaka, MD; Hiroshi Inoue, MD; \\ Yohko Kawai, MD; Takenori Yamaguchi, MD; Shinichiro Uchiyama, MD; \\ Masayasu Matsumoto, MD; Satoshi Ogawa, MD
}

\begin{abstract}
Background: Edoxaban is a once-daily (QD) oral, direct factor Xa inhibitor in clinical development for the prevention of stroke in patients with non-valvular atrial fibrillation (NVAF). The aim of this study was to evaluate the safety of edoxaban in Japanese patients with NVAF.
\end{abstract}

Methods and Results: A total of 536 NVAF patients (CHADS2 $\geq 1$ ) were randomized to receive double-blinded edoxaban 30, 45, or 60 mg QD or open-label warfarin (international normalized ratio [INR] 2.0-3.0 for age $<70$ years; 1.6-2.6 for age $\geq 70$ years) for 12 weeks. The primary endpoint was the incidence of all bleeding events (major, clinically relevant non-major, and minor bleeds). Patients underwent CT and/or MRI to assess asymptomatic intracranial hemorrhage (ICH). Secondary endpoints included thromboembolic events and pharmacodynamic indices. The mean incidence of all bleeding events for edoxaban 30,45 , and $60 \mathrm{mg}$, and warfarin was $18.5 \%, 22.4 \%, 27.7 \%$, and $20.0 \%$, respectively. There were no statistically significant differences among the edoxaban groups and no significant differences from the warfarin group. There were no asymptomatic $\mathrm{ICH}$ events in any group. One episode of cerebral infarction was observed in the edoxaban 45-mg group. Subgroup analysis suggested low body weight $(\leq 60 \mathrm{~kg})$ was associated with higher bleeding risk.

Conclusions: Edoxaban 30, 45, and 60mg QD in patients with NVAF was associated with a numerical increase in all bleeding across the dose range, but this was not statistically significant, nor was any dose compared with warfarin. (Circ $J$ 2012; 76: 1840-1847)

Key Words: Anticoagulants; Atrial fibrillation; Edoxaban; Warfarin

A nticoagulation with vitamin $\mathrm{K}$ antagonists (VKAs) reduces the incidence of ischemic stroke and systemic embolization in patients with non-valvular atrial fibrillation (NVAF), ${ }^{1}$ and is recommended by treatment guidelines for moderate- to high-risk patients with NVAF.,3 However, VKAs are used only in approximately one-half of indicated patients ${ }^{4,5}$ because of unpredictable pharmacokinetics (PK) and pharmacodynamics (PD), drug and food interactions, and genetic variability in response, which necessitate frequent monitoring and dose adjustments. ${ }^{6}$

\section{Editorial p1826}

Edoxaban, a new oral anticoagulant that specifically and directly inhibits activated coagulation factor $\mathrm{Xa}(\mathrm{FXa}){ }^{7}$ is in clinical development for the prevention of stroke and systemic embolism in patients with NVAF. Edoxaban has linear PK, with approximately $62 \%$ oral bioavailability. ${ }^{8}$ Maximum plasma concentrations are reached in $1-3 \mathrm{~h}$ with a plasma elimination half-life of 8-10h. ${ }^{9}$ In 2 earlier phase II studies in warfarin-naïve Japanese patients with NVAF, edoxaban at

Received October 6, 2011; revised manuscript received March 6, 2012; accepted March 26, 2012; released online May 18 , 2012 Time for primary review: 56 days

Division of Cardiology, The Cardiovascular Institute, Tokyo (T. Yamashita); Clinical Research Institute, National Hospital Organization Osaka National Hospital, Osaka (Y. Koretsune); Department of Cerebrovascular Disease, National Hospital Organization Kyushu Medical Center, Fukuoka (M.Y.); Second Department of Internal Medicine, University of Toyama, Toyama (H.I.); Preventive Health Examination Center, International University of Health and Welfare, Tokyo (Y. Kawai); Cerebrovascular Division, National Cerebral and Cardiovascular Center, Suita (T. Yamaguchi); Department of Neurology, Tokyo Women's Medical University School of Medicine, Tokyo (S.U.); Department of Clinical Neuroscience and Therapeutics, Hiroshima University Graduate School of Biomedical Sciences, Hiroshima (M.M.); and Department of Medicine, International University of Health and Welfare Mita Hospital, Tokyo (S.O.), Japan

Mailing address: Takeshi Yamashita, MD, Division of Cardiology, The Cardiovascular Institute, 3-2-19 Nishiazabu, Minato-ku, Tokyo 106-0031, Japan. E-mail: yamt-tky@umin.ac.jp

ISSN-1346-9843 doi:10.1253/circj.CJ-11-1140

All rights are reserved to the Japanese Circulation Society. For permissions, please e-mail: cj@j-circ.or.jp 
doses up to $60 \mathrm{mg}$ twice daily (BID) for a maximum of 4 weeks was well tolerated, and biomarker evaluations suggested suppression of endogenous thrombogenesis at doses $\geq 5 \mathrm{mg} .{ }^{10} \mathrm{~A}$ larger phase II study in Europe and North America comparing edoxaban $30 \mathrm{mg}$ once daily (QD), 30 mg BID, $60 \mathrm{mg}$ QD, and $60 \mathrm{mg}$ BID for 12 weeks in patients with NVAF and a CHADS2 score of $\geq 2$ demonstrated that the incidence of major or clinically relevant non-major bleeding with edoxaban 30 and $60 \mathrm{mg}$ QD was similar to that of warfarin. ${ }^{11}$

The aim of the present study was to assess the incidence of bleeding associated with edoxaban $30 \mathrm{mg}, 45 \mathrm{mg}$, and $60 \mathrm{mg}$ QD compared with warfarin in Japanese patients with NVAF.

\section{Methods}

\section{Study Design}

This was a multicenter, randomized, dose-ranging study of edoxaban (double-blind to dose) and open-label warfarin performed at 61 study sites in Japan. The protocol was approved by an institutional review board at each participating center, and all patients provided written informed consent. This study was conducted in accordance with principles originating in the Declaration of Helsinki and in compliance with Good Clinical Practice guidelines and local regulatory requirements.

\section{Patients}

Patients aged $\geq 20$ years with NVAF documented by electrocardiogram at least twice within 12 months and a CHADS2 score $\geq 1$ were eligible. Patients were excluded if they had any of the following: history of intracranial, intraocular (excluding subconjunctival), intraspinal, retroperitoneal, or atraumatic intra-articular bleeding; gastrointestinal bleeding during the past year; hemoglobin $<100 \mathrm{~g} / \mathrm{L}$ or platelets $<100,000 / \mu 1$ at screening; cerebral infarction or transient ischemic attack that occurred within 30 days; history of valvular surgery; concurrent treatment with anticoagulants (excluding warfarin); comorbid rheumatic valvular disease, infective endocarditis, atrial myxoma, or serious heart disease; left ventricular or left atrial thrombus; renal or hepatic dysfunction; body weight $<40 \mathrm{~kg}$; pregnancy or lactating.

\section{Study Treatments}

Patients were randomly assigned to double-blinded edoxaban $30 \mathrm{mg}$, $45 \mathrm{mg}$, or $60 \mathrm{mg}$ QD or open-label warfarin doseadjusted to a target prothrombin time expressed as an international normalized ratio (PT-INR) of 2.0-3.0 and 1.6-2.6, for patients aged $<70$ and $\geq 70$ years, respectively, in accordance with Japanese treatment guidelines. ${ }^{3,12}$ Based on prospective study results in Japanese patients, ${ }^{13}$ Japanese treatment guidelines recommend a target INR of 1.6-2.6 for patients aged 70 or older on warfarin treatment. After randomization, pretreatment PT-INR was measured for warfarin-experienced patients. Patients randomized to edoxaban with previous warfarin exposure and a PT-INR $\geq 2.0$ were entered into a run-in period for $\leq 6$ weeks to reduce the PT-INR to $<2.0$. In the warfarin group, warfarin-naïve patients and warfarin-experienced patients aged $<70$ years with a PT-INR $<2.0$ or $>3.0$ (PT-INR $<1.6$ or $>2.6$ for patients aged $\geq 70$ years) began a run-in period with warfarin for $\leq 6$ weeks to achieve a target PT-INR of 2.0-3.0 (1.6-2.6 in patients aged $\geq 70$ years). Treatment was initiated on attaining the target PT-INR. Patients not requiring the run-in started study treatment the day after pretreatment assessment. Patients were randomized using the specifications of dynamic allocation procedures. Treatment was assigned using the biased coin method, with the presence/absence of prophylactic warfarin upon registration as an adjustment factor. Duration of the study drug treatment was 12 weeks, with follow-up at 4 and 8 weeks. Medication compliance was assessed by collecting remaining drugs at every visit and patient interviews at study visits.

\section{Outcome Measures}

The primary endpoint was the incidence of all bleeding events (major, clinically relevant non-major, and minor bleeding), including asymptomatic intracranial hemorrhage ( $\mathrm{ICH})$, during the 12-week treatment period. Major bleeding was defined as life-threatening bleeding; intracranial, intraspinal, intraocular (excluding subconjunctival), retroperitoneal, intraarticular, or intrapericardial bleeding; clinically overt bleeding accompanied by a decrease in hemoglobin of $\geq 20 \mathrm{~g} / \mathrm{L}$; or bleeding requiring transfusion of $\geq 4$ units of blood ( 1 unit= approximately $200 \mathrm{ml}$ ). Clinically relevant non-major bleeding was defined as bleeding not meeting the criteria for major bleeding, but consisting of hematoma $\geq 5 \mathrm{~cm}$ in diameter; epistaxis or gingival bleeding $\geq 5 \mathrm{~min}$ in the absence of external factors; gastrointestinal bleeding; gross hematuria persistent $24 \mathrm{~h}$ after onset; asymptomatic cerebral hemorrhage; or other bleeding requiring discontinuation of study treatment. Minor bleeding was defined as bleeding not meeting the definition of major or clinically relevant non-major bleeding, including gross hematuria, urinary occult blood graded " $2+$ " or more severe, or urinary occult blood graded "+" and urinary sediment (red blood cell) of $\geq 10 / \mathrm{HPF}$; or subcutaneous bleeding, epistaxis, and gingival bleeding occurring in the absence of external factors. All bleeding events were assessed by an independent Event Assessment Committee.

Asymptomatic ICH was defined as a newly detected hemorrhage on computed tomography (CT) or magnetic resonance imaging (MRI; both T1 and T2) based on assessment of preand post-treatment images. All images were assessed by an Asymptomatic ICH Committee that was blinded to treatment assignment.

Secondary endpoints consisted of thromboembolic events including stroke assessed by an independent Event Assessment Committee; PD parameters (D-dimer, prothrombin fragment $1+2\left[\mathrm{~F}_{1+2}\right]$, and thrombin anti-thrombin complex); plasma drug concentration after 4 and 8 weeks of treatment; and safety endpoints including adverse events (AEs) and adverse drug reactions (ADRs) during treatment. Bleeding-related AEs included major, clinically relevant non-major, minor, and other bleeding (not classified under the category of bleeding events). The incidence of both L-aspartate aminotransferase (AST) (glutamic oxaloacetic acid transaminase [GOT]) and L-alanine aminotransferase (ALT) (glutamic pyruvic acid transaminase [GPT]) $\geq 3$ times the upper limit of normal (ULN) and total bilirubin $\geq 2$ times ULN, or either AST (GOT) or ALT $(\mathrm{GPT}) \geq 3$ times ULN and total bilirubin $\geq 2$ times ULN was also recorded.

\section{PK and PD Evaluations}

Samples for PK measurements were collected at predose, $1-3 \mathrm{~h}$ postdose, and $4-8 \mathrm{~h}$ postdose in week 4 and at predose in week 8. Plasma concentrations of edoxaban were determined using a liquid chromatography tandem mass spectrometry method. The lower limit of quantification for edoxaban in plasma was $1 \mu \mathrm{g} / \mathrm{L}$. Samples for PD measurements were collected as follows: in the edoxaban groups at trough, and 1-3h postdose in week 4 , at predose in week 8 or 12 , or at the time of discontinuation, and at 4 and 8 weeks after study end or discontinuation; in the warfarin group at trough, in weeks 4 , 


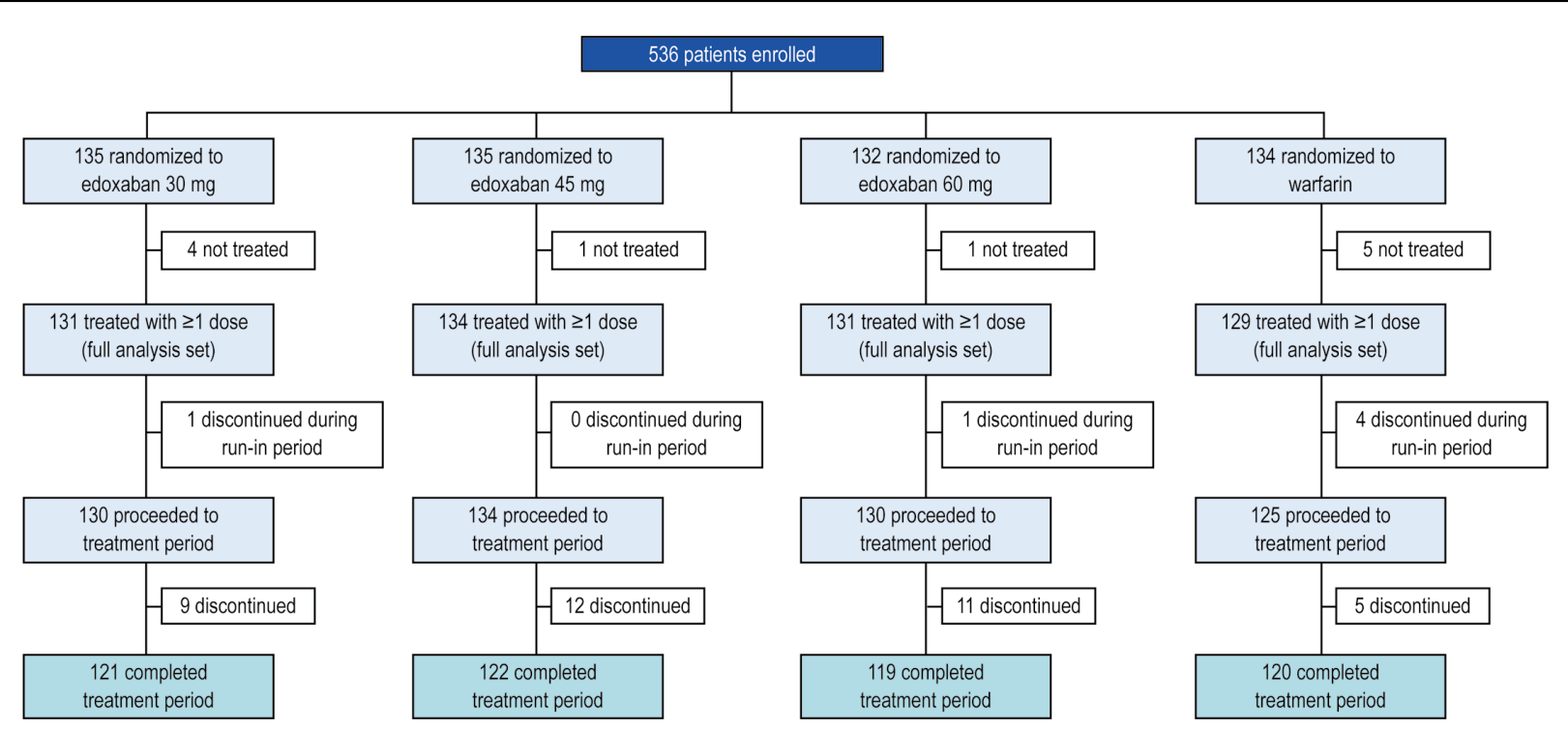

Figure 1. Patient disposition.

\begin{tabular}{|c|c|c|c|c|}
\hline & \multirow{2}{*}{$\begin{array}{c}\text { Warfarin } \\
(n=129)\end{array}$} & \multicolumn{3}{|c|}{ Edoxaban $(n=396)$} \\
\hline & & $\begin{array}{c}30 \mathrm{mg} Q D \\
(\mathrm{n}=131)\end{array}$ & $\begin{array}{c}45 \mathrm{mg} \text { QD } \\
(\mathrm{n}=134)\end{array}$ & $\begin{array}{c}60 \mathrm{mg} Q D \\
(\mathrm{n}=131)\end{array}$ \\
\hline Age, years, mean & 68.8 & 69.4 & 69.5 & 68.4 \\
\hline \multicolumn{5}{|l|}{ Gender, $\mathrm{n}$} \\
\hline Male & 107 & 110 & 109 & 107 \\
\hline Female & 22 & 21 & 25 & 24 \\
\hline Weight, kg, mean & 64.9 & 65.8 & 63.8 & 66.0 \\
\hline BMI, kg/m², mean & 24.44 & 24.62 & 24.06 & 24.71 \\
\hline \multicolumn{5}{|l|}{ Risk factor, n (\%) } \\
\hline Hypertension & $92(71)$ & $98(75)$ & $96(72)$ & $97(74)$ \\
\hline Diabetes & $40(31)$ & $24(18)$ & $28(21)$ & $28(21)$ \\
\hline $\mathrm{CHF}$ & $43(33)$ & $31(24)$ & $37(28)$ & $32(24)$ \\
\hline History of stroke/TIA & $39(30)$ & $30(23)$ & $38(28)$ & $39(30)$ \\
\hline Age $\geq 75$ years & $35(27)$ & $38(29)$ & $38(28)$ & $39(30)$ \\
\hline \multicolumn{5}{|l|}{ CHADS2 score } \\
\hline Mean & 2.2 & 1.9 & 2.1 & 2.1 \\
\hline Median & 2 & 2 & 2 & 2 \\
\hline History of warfarin, $\mathrm{n}(\%)$ & $111(86)$ & $111(85)$ & $112(84)$ & $111(85)$ \\
\hline Current smoking, $\mathrm{n}(\%)$ & $21(16)$ & $23(18)$ & $18(13)$ & $24(18)$ \\
\hline Current alcohol use, $\mathrm{n}(\%)$ & $84(65)$ & $85(65)$ & $80(60)$ & $74(57)$ \\
\hline $\mathrm{CrCl}<0.835 \mathrm{ml} / \mathrm{s}, \mathrm{n}(\%)$ & $16(12)$ & $13(10)$ & $21(16)$ & $16(12)$ \\
\hline Concomitant aspirin use & $29(23)$ & $32(25)$ & $33(25)$ & $38(29)$ \\
\hline
\end{tabular}

$\mathrm{QD}$, once daily; $\mathrm{BMI}$, body mass index; $\mathrm{CHF}$, congestive heart failure; TIA, transient ischemic attack; $\mathrm{CrCl}$, creatinine clearance.

8 , and 12 or at the time of discontinuation, and at 4 and 8 weeks after study end or discontinuation.

\section{Statistical Analysis}

On the basis of the results of a previous warfarin-controlled study of ximelagatran in patients with $\mathrm{NVAF},{ }^{14}$ it was estimated that the incidence of bleeding events in the warfarin group would be $15 \%$. Based on the assumption of a similar incidence of bleeding events with edoxaban, sample size was estimated to require 104 patients to achieve a $95 \%$ confidence interval (CI) divided by 2 for the intergroup difference determined using the Score method. The target number of patients was set at 125 per group, assuming that $20 \%$ of the patients would be excluded from the analysis.

Primary endpoint analyses were performed in the full analysis set (FAS), defined as all patients who received at least 1 
dose of the study drug. The incidence of bleeding events and 95\% CIs were calculated for each treatment group. The difference in incidence of bleeding events between the warfarin group and each edoxaban group, and 95\% CIs were calculated. A paired comparison between the edoxaban groups was performed using the $\chi^{2}$ test as well as Fisher's exact test. The hypotheses (null hypothesis: incidence of bleeding in all edoxaban groups is the same; alternative hypothesis: incidence of bleeding for edoxaban $30 \mathrm{mg} \leq 45 \mathrm{mg} \leq 60 \mathrm{mg}$ ) were tested using the Cochran-Armitage test with a 1 -sided 0.025 significance level. The time to bleeding events was analyzed using the proportional hazard model, and cumulative incidence of bleeding was analyzed by the Kaplan-Meier method. Exploratory analyses of the primary endpoint were performed using a logistic model with major, major and clinically relevant nonmajor, or all bleeding events as objective variables. The variables were selected using a stepwise procedure with a 2 -sided 0.15 significance level for both inclusion and exclusion criteria.

The incidence and 95\% CIs were calculated for thromboembolic events. The PK and PD analysis sets were defined as patients in the FAS with valid plasma edoxaban concentrations, and a PD index or biomarker data measured at $\geq 1$ time points, respectively. Plasma drug concentrations, PD parameters, and biomarkers were summarized at each time point by treatment group. Mean and median $\mathrm{C}_{\text {min }}$ (plasma concentration of edoxaban in the blood sample drawn just before administration of the study drug at day 28) and 95\% CIs were calculated.

Incidence of AEs and ADRs and 95\% CIs were calculated by treatment group; the difference in incidence between treatment groups and 95\% CIs were also calculated.

\section{Results}

A total of 536 patients were enrolled in the study between April 2007 and July 2008; 525 patients were included in the analysis of the primary endpoint (Figure 1). There were no differences in patient demographics or baseline characteristics (Table 1). Overall, time within target INR range ${ }^{15}$ was $83 \%$ for patients aged $\geq 70$ years (INR 1.6-2.6), and 73\% for patients aged $<70$ years (INR 2.0-3.0).

\section{Primary Endpoint}

Bleeding The incidence of all bleeding events increased with increasing edoxaban doses and was higher in the edoxaban 60-mg group than in the warfarin group (Figure 2, Table 2). A comparison between edoxaban doses showed no significant differences among edoxaban doses or between any edoxaban group and warfarin. The incidence of major, or major and clinically relevant non-major bleeding also increased with increasing edoxaban doses, but the difference was not significant. There was 1 fatal cerebral hemorrhage in the edoxaban 60-mg group. Of the 536 patients enrolled, 17 patients did not fulfill the assessment criteria for asymptomatic ICH. The remaining 519 patients (391 edoxaban, 128 warfarin) were evaluated: 431 CT, 81 MRI, and 7 CT/MRI. There were no cases of asymptomatic ICH. Between treatment groups, significant differences in blood pressure during the treatment period were not found.

Although a trend of dose-related increased bleeding was observed, a significant dose response was not found with edoxaban for all, major, or major and clinically relevant nonmajor bleeding events (Cochran-Armitage test: $\mathrm{P}=0.038, \mathrm{P}=$ 0.134 , and $\mathrm{P}=0.058$, respectively). The incidence of bleedingrelated AEs increased dose-dependently (Cochran-Armitage test: $\mathrm{P}=0.002$ [1-sided, 0.025 significance level]) and was significantly higher in the edoxaban $60-\mathrm{mg}$ group compared with the 30-mg group ( $\chi^{2}$ test: $\mathrm{P}=0.003$ ). Hazard ratios for all bleeding events relative to the warfarin group were $0.939,1.124$, and 1.458 in the edoxaban $30-\mathrm{mg}$, 45-mg, and 60-mg groups, respectively; all of the $95 \%$ CIs included 1.

In an exploratory subgroup analysis, logistic regression suggested body weight $(\leq 60 \mathrm{~kg})$ as an important covariate for all bleeding events, including major and clinically relevant nonmajor bleeding. When stratified by body weight, the incidence of major and clinically relevant non-major bleeding was higher in the $\leq 60-\mathrm{kg}$ subgroup than in the $>60-\mathrm{kg}$ subgroup for all doses (Figure 3). The incidence of all bleeding events in patients $\leq 60 \mathrm{~kg}$ was almost twice that of patients $>60 \mathrm{~kg}$ in the edoxaban $60-\mathrm{mg}$ and warfarin groups. Concomitant administration of aspirin was also an important covariate for bleeding events, based on subgroup analysis and logistic regression analysis (data not shown).

\section{Secondary Endpoints}

Thromboembolic Events There was only 1 thromboembolic event in the edoxaban 45-mg group. The patient had a history of cerebral infarction with a CHADS2 score $=2$. Cerebral infarction was diagnosed by the investigator based on signs and symptoms; a CT scan of the brain revealed no hemorrhagic lesions or new infarcted lesions. The investigator's evaluation was supported by the Event Assessment Committee.

PK/PD Edoxaban dose dependently prolonged PT-INR at $1-3 \mathrm{~h}$ postdose in treatment weeks 4 and $12(\mathrm{P}<0.001)$. Prolongation of PT-INR with edoxaban was more pronounced in warfarin-naïve patients. Similar results were observed with PT and activated partial thromboplastin time.

In warfarin-naïve patients, the D-dimer decreased in 12 weeks compared with the pretreatment values in all edoxaban groups and the warfarin group. In warfarin pretreated patients, D-dimer did not change in all edoxaban groups and the warfarin group (Figure 4). There was also a trend for decreases in $\mathrm{F}_{1+2}$ in the warfarin-naïve subgroup (data not shown).

$\mathrm{C}_{\text {min }}$ increased with increasing edoxaban doses. When patients were stratified by body weight, $\mathrm{C}_{\min }$ in the $\leq 60-\mathrm{kg}$ subgroup was higher than the $\mathrm{C}_{\min }$ in the $>60-\mathrm{kg}$ subgroup with all doses; in the edoxaban $60-\mathrm{mg}$ group, $\mathrm{C}_{\min }$ in the $\leq 60-\mathrm{kg}$ subgroup was 1.8 times that in the $>60-\mathrm{kg}$ subgroup.

\section{AEs}

Compared with warfarin, the incidence of AEs (mostly mild) was lower in the edoxaban 30-mg group and higher in the 45$\mathrm{mg}$ and $60-\mathrm{mg}$ groups. The most common AEs in the edoxaban groups were: blood in the urine, nasopharyngitis, epistaxis, subcutaneous hemorrhage, and increased gamma-glutamyltransferase. The incidence of severe AEs was $0.8 \%$ (1/130) in the edoxaban $60-\mathrm{mg}$ group, $1.6 \%(2 / 125)$ in the warfarin group, and none in the edoxaban 30-mg and 45-mg groups. In the warfarin group, 1 patient had congestive heart failure and 1 patient experienced sudden death.

In the edoxaban 60-mg group, AST (GOT) or ALT (GPT) levels were each elevated $\geq 3$ times ULN in 2 patients; 1 patient in the warfarin group had ALT (GPT) $\geq 3$ times ULN. One patient had AST (GOT) or ALT (GPT) $\geq 3$ times ULN and a total bilirubin $\geq 2$ times ULN. This patient was randomized to the edoxaban 60-mg group and had a drinking habit. Levels decreased without intervention. 


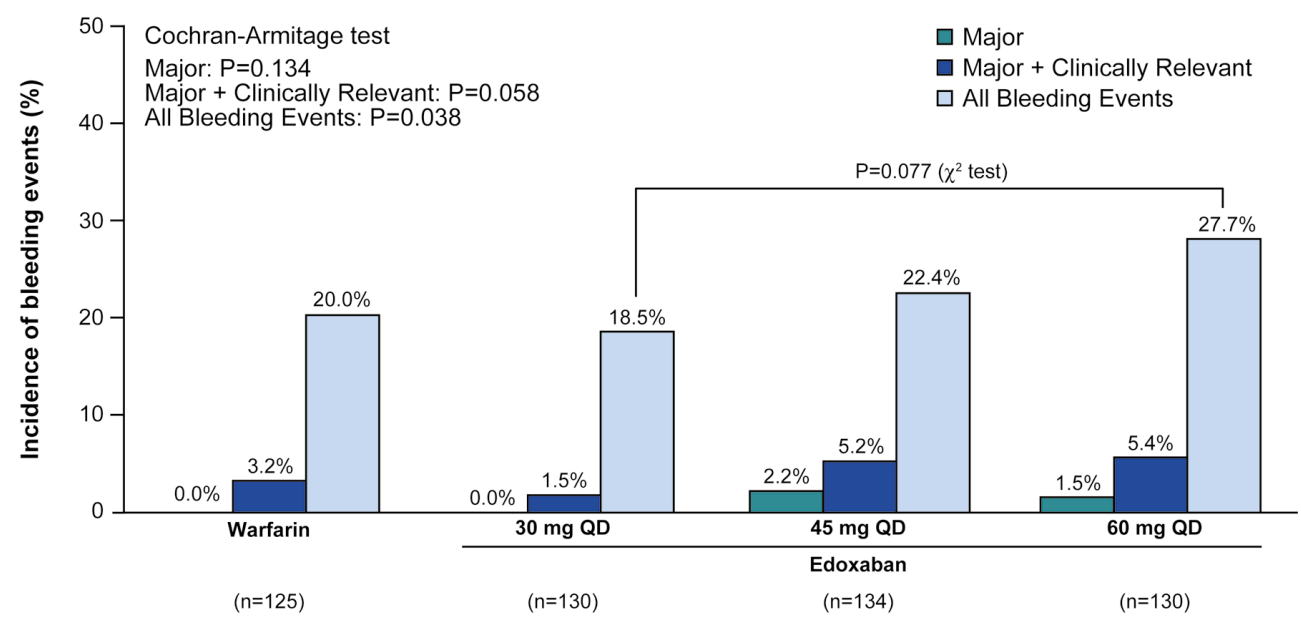

Figure 2. Incidence of bleeding events.

\begin{tabular}{|c|c|c|c|c|}
\hline & \multirow{2}{*}{$\begin{array}{l}\text { Warfarin } \\
(n=125)\end{array}$} & \multicolumn{3}{|c|}{ Edoxaban } \\
\hline & & $\begin{array}{c}30 \mathrm{mg} Q D \\
(\mathrm{n}=130)\end{array}$ & $\begin{array}{c}45 \mathrm{mg} Q D \\
(n=134)\end{array}$ & $\begin{array}{c}60 \mathrm{mg} Q D \\
(n=130)\end{array}$ \\
\hline \multicolumn{5}{|l|}{ Major bleeding } \\
\hline $\mathrm{n}(\%)$ & $0(0.0)$ & $0(0.0)$ & $3(2.2)$ & $2(1.5)$ \\
\hline $95 \% \mathrm{Cl}$ & $(0.0,3.0)$ & $(0.0,2.9)$ & $(0.8,6.4)$ & $(0.4,5.4)$ \\
\hline Difference from warfarin & - & 0.0 & 2.2 & 1.5 \\
\hline $95 \% \mathrm{Cl}$ for difference in incidence & - & $(0.0,0.0)$ & $(-0.3,4.7)$ & $(-0.6,3.7)$ \\
\hline \multicolumn{5}{|c|}{$\begin{array}{l}\text { Major and clinically relevant non-major } \\
\text { bleeding }\end{array}$} \\
\hline $\mathrm{n}(\%)$ & $4(3.2)$ & $2(1.5)$ & $7(5.2)$ & $7(5.4)$ \\
\hline $95 \% \mathrm{Cl}$ & $(1.3,7.9)$ & $(0.4,5.4)$ & $(2.6,10.4)$ & $(2.6,10.7)$ \\
\hline Difference from warfarin & - & -1.7 & 2.0 & 2.2 \\
\hline $95 \% \mathrm{Cl}$ for difference in incidence & - & $(-5.4,2.1)$ & $(-2.8,6.9)$ & $(-2.8,7.1)$ \\
\hline \multicolumn{5}{|l|}{ All bleeding } \\
\hline n (\%) & $25(20.0)$ & $24(18.5)$ & $30(22.4)$ & $36(27.7)$ \\
\hline $95 \% \mathrm{Cl}$ & $(13.9,27.9)$ & $(12.7,26.0)$ & $(16.2,30.2)$ & $(20.7,35.9)$ \\
\hline Difference from warfarin & - & -1.5 & 2.4 & 7.7 \\
\hline $95 \% \mathrm{Cl}$ for difference in incidence & - & $(-11.2,8.1)$ & $(-7.6,12.3)$ & $(-2.7,18.1)$ \\
\hline \multicolumn{5}{|l|}{ Bleeding-related AEs } \\
\hline Patients with events, $\mathrm{n}(\%)$ & $36(28.8)$ & $38(29.2)$ & $49(36.6)$ & $61(46.9)$ \\
\hline $95 \% \mathrm{Cl}$ & $(21.6,37.3)$ & $(22.1,37.6)$ & $(28.9,45.0)$ & $(38.6,55.5)$ \\
\hline Difference from warfarin & - & 0.4 & 7.8 & 18.1 \\
\hline $95 \% \mathrm{Cl}$ for difference in incidence & - & $(-10.7,11.6)$ & $(-3.6,19.1)$ & $(6.4,29.8)$ \\
\hline
\end{tabular}

All bleeding: Major + clinically relevant non-major + minor bleeding.

Bleeding-related AEs: Major + clinically relevant non-major + minor + other bleeding.

$\mathrm{QD}$, once daily; $\mathrm{Cl}$, confidence interval; $\mathrm{AEs}$, adverse events.

\section{Discussion}

The present study provided us with several findings of interest. Edoxaban caused a trend of dose-dependent increase in the incidence of all bleeding events, and the risk of all bleeding was numerically higher in the edoxaban $60-\mathrm{mg}$ group than in the warfarin group, although these differences were not statistically significant. At the same time, the risk of major, or major and clinically relevant non-major bleeding in each edoxaban group was not statistically different from that in the warfarin group, even when asymptomatic ICH adjudicated by the asymptomatic ICH committee was included as a clinically relevant bleeding event on the basis that asymptomatic ICH is a risk factor for future symptomatic ICH in patients on warfarin. ${ }^{16,17}$ Some exploratory analyses were conducted to determine the cause of the dose-related trend in bleeding risk and to confirm the clinical meaning of these observations.

The exploratory analyses suggested that the risk of major and clinically relevant non-major bleeding, or all bleeding in underweight patients $(\leq 60 \mathrm{~kg})$ was higher than that in the 

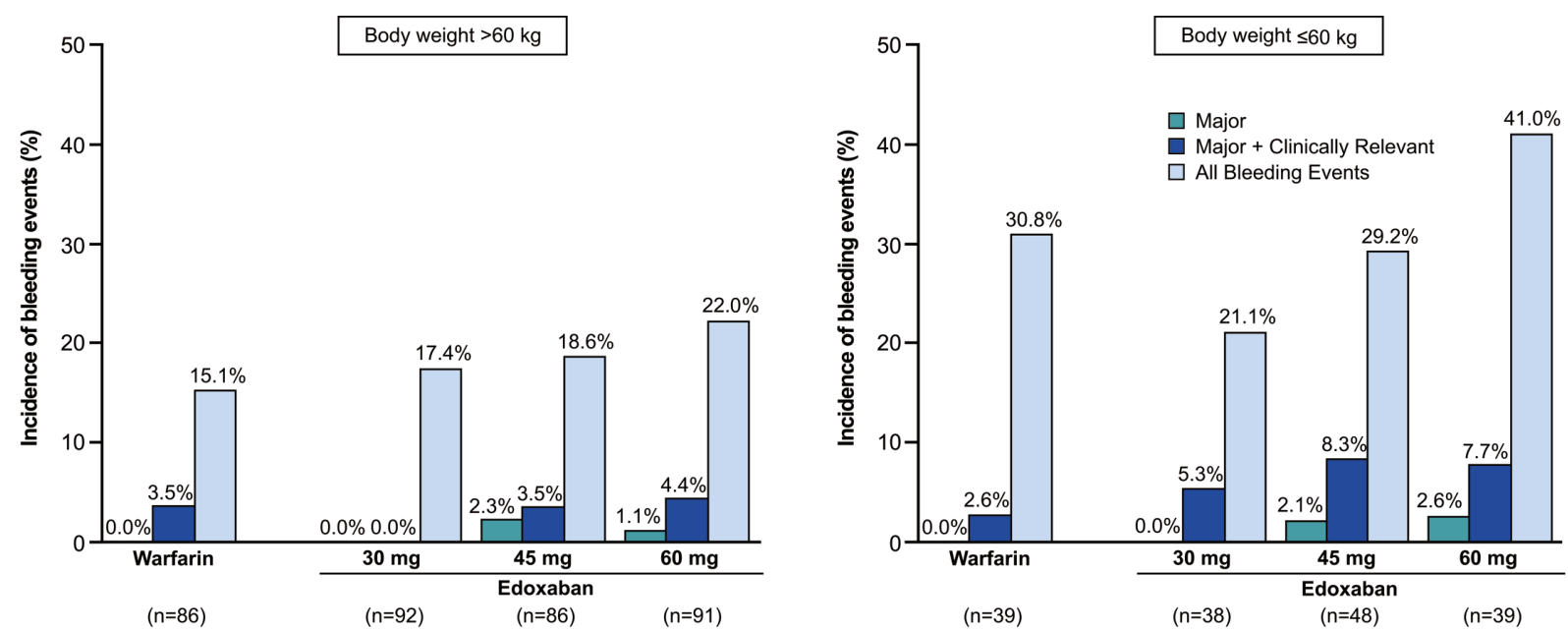

Figure 3. Subgroup analysis by body weight (incidence of bleeding events).
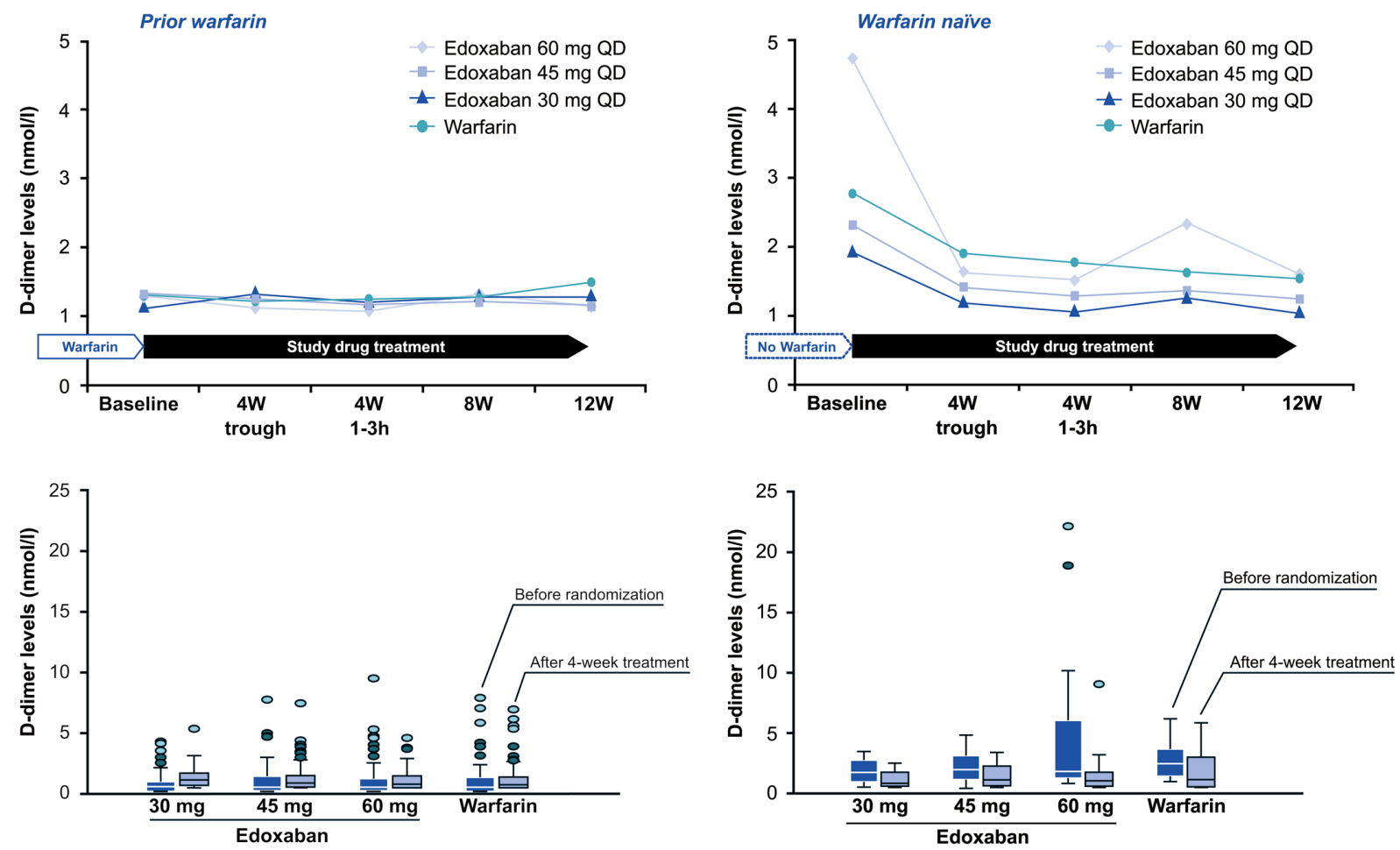

Figure 4. D-dimer distributions in patients with and without prior warfarin treatment. Upper figures indicate the change in D-dimer levels in each treatment group. Lower figures indicate distribution of D-dimer levels before randomization and after 4 weeks of treatment in each treatment group.

higher weight patients $(>60 \mathrm{~kg})$ in each edoxaban group, and that the low body weight was an independent risk factor for increased major and clinically relevant bleeding, or all bleeding in the edoxaban groups. Actually, the incidence of major and clinically relevant non-major bleeding in the edoxaban 45-mg and 60-mg groups was approximately thrice that of the warfarin group, and the incidence of all bleeding in the edoxaban 60-mg group was also approximately twice that of the warfarin group in the underweight patients. These body weightdependent differences in the bleeding risks might be, at least in part, associated with the primary analysis results and also the trend in dose-dependent increasing risks in the total pa- 
tients. Dose reduction could be beneficial for underweight patients $(\leq 60 \mathrm{~kg}$ ) receiving edoxaban $45 \mathrm{mg}$ and $60 \mathrm{mg}$ QD.

In another dose-finding study of patients with NVAF conducted in Europe and North America, the incidence of bleeding in the edoxaban 60-mg QD group was similar to warfarin. ${ }^{11}$ The present study differs from the other dose-finding study with respect to: (1) edoxaban 45-mg QD dose was evaluated; and (2) when the results of edoxaban $30 \mathrm{mg}$ and $60 \mathrm{mg}$ QD were compared, there was a large number of major plus clinically relevant non-major bleeding events in the edoxaban 60-mg group in the study. However, several differences in the backgrounds of the enrolled patients should be taken into consideration in comparing the present study results with previous studies; these include race, a higher proportion of males, lower proportion of warfarin-naïve subjects and aspirin users, and lower body weight. In particular, the mean body weight in this study was approximately $65 \mathrm{~kg}$, while it was approximately $88 \mathrm{~kg}$ for the study conducted in Europe and North America. ${ }^{11}$ There were $<5 \%$ of patients with a body weight $\leq 60 \mathrm{~kg}$ in the other study, which is very few in comparison to this study.

It has been reported that the risk of bleeding with anticoagulant or antiplatelet therapy is higher in Asian patients including Japanese than in Western patients. ${ }^{18,19}$ Some potential factors that cause the difference in bleeding risk with antithrombotic therapy between races have been reported; however, a definite cause has not been identified. ${ }^{20-23}$ Also, our study revealed that low body weight caused increased exposure to edoxaban and risk of bleeding in a Japanese population. Therefore, low body weight was assumed to be an independent risk factor of edoxaban for increased bleeding. Collectively, the difference between this study and the other study might be explained, at least in part, by ethnic difference and body weight.

This study was not designed to assess the effect of edoxaban on preventing thromboembolic events in patients with NVAF. However, treatment with edoxaban decreased thrombotic biomarkers, suggesting its potential for preventing thromboembolic events. In a phase II trial with AZD0837, a direct thrombin inhibitor, ${ }^{24}$ a dose-dependent decrease in D-dimer was similarly seen in VKA-naïve patients; this result is mostly in agreement with this study and might be a characteristic common to the new anticoagulants.

This study has several limitations: (1) an open-label warfarin management group; (2) a small number of patients; (3) the target INR for patients aged $\geq 70$ years on warfarin treatment was managed differently from that of other countries based on the Japanese treatment guideline; (4) a short treatment period (12 weeks); and (5) the study was not powered to assess the efficacy of edoxaban. Also, bleeding is dependent on many factors, including baseline patient characteristics (eg, demographics, comorbidity, and disease status), prior warfarin administration, and the duration of administration of a new anticoagulant. Further studies will be needed on this issue.

The ENGAGE AF-TIMI 48 study of edoxaban (NCT 00781391) is now underway in 46 countries, including Japan, to assess edoxaban $30 \mathrm{mg}$ and $60 \mathrm{mg}$ QD vs. warfarin for the prevention of stroke and systemic embolic events in patients with NVAF. ${ }^{25}$ The study will also provide an opportunity to investigate differences in the risk of bleeding between Japanese and Westerners, identify factors that can influence bleeding risk, and determine the effect of dose adjustment of edoxaban on efficacy and safety.

In conclusion, these study results suggest that edoxaban at doses of $30 \mathrm{mg}, 45 \mathrm{mg}$, and $60 \mathrm{mg}$ QD in patients with NVAF is associated with a slight, but not statistically significant increase in bleeding compared with warfarin. Subgroup analysis suggests that an edoxaban dose reduction might be considered in patients with low body weight $(\leq 60 \mathrm{~kg})$.

\section{Acknowledgments}

This study was funded by Daiichi Sankyo Co, Ltd (Tokyo, Japan). The authors gratefully acknowledge the Event Evaluation Committee and Data Monitoring Committee members as well as the principal investigators and site staff who assisted with this research. For a list of Committee members and study principal investigators and locations, please see Appendix. The authors would also like to acknowledge writing assistance provided by Sameena Azmi, PhD, Jennifer Ciafullo, MPH, and Peter Maynard, PhD, and editorial assistance by Quintiles Medical Communications (Parsippany, NJ, USA), which was funded by Daiichi Sankyo Co, Ltd. Daiichi Sankyo Co, Ltd, had input on the study design and data analysis/interpretation of results and wrote the clinical study report. All authors (T. Yamashita, Y. Koretsune, M.Y., H.I., Y. Kawai, T. Yamaguchi, S.U., M.M., S.O.) are Steering Committee members and contributed to the study concept and data analysis/interpretation of results and independently drafted, critically revised, and approved the final manuscript.

\section{Disclosures}

T. Yamashita: Consultant, Paid Instructor-Daiichi Sankyo Co, Ltd, Nippon Boehringer Ingelheim Co, Ltd, Bayer Yakuhin, Ltd; Paid Instructor-Eisai Co, Ltd; National Lead Investigator-Daiichi Sankyo Co, Ltd.

Y. Koretsune: Consultant, Paid Instructor-Daiichi Sankyo Co, Ltd, Eisai Co, Ltd, Nippon Boehringer Ingelheim Co, Ltd, Bayer Yakuhin, Ltd; Paid Instructor-Bristol-Myers Squibb; National Lead Investigator-Daiichi Sankyo Co, Ltd.

M. Yasaka: Consultant-Daiichi Sankyo Co, Ltd, Nippon Boehringer Ingelheim Co, Ltd, Pfizer Japan, Inc.

H. Inoue: Consultant-Daiichi Sankyo Co, Ltd, Nippon Boehringer Ingelheim Co, Ltd, Eisai Co, Ltd.

Y. Kawai: Consultant-Toyama Chemical, Daiichi Sankyo Co, Ltd, Bayer Yakuhin, Ltd.

T. Yamaguchi: Consultant-Nippon Boehringer Ingelheim Co, Ltd, Daiichi Sankyo Co, Ltd.

S. Uchiyama: Consultant-Astellas Pharma Inc, Bayer Yakuhin, Ltd, Nippon Boehringer Ingelheim Co, Ltd.

M. Matsumoto: Consultant-Bayer Yakuhin, Ltd, Pfizer Japan, Inc, Daiichi Sankyo Co, Ltd.

S. Ogawa: Consultant-Bayer Yakuhin, Ltd, Pfizer Japan, Inc; ShareholderAstellas Pharma, Inc; Paid Instructor-sanofi-aventis.

\section{References}

1. Hart RG, Pearce LA, Aguilar MI. Meta-analysis: Antithrombotic therapy to prevent stroke in patients who have nonvalvular atrial fibrillation. Ann Intern Med 2007; 146: 857-867.

2. Singer DE, Albers GW, Dalen JE, Fang MC, Go AS, Halperin JL, et al. Antithrombotic therapy in atrial fibrillation: American College of Chest Physicians Evidence-Based Clinical Practice Guidelines (8th edition). Chest 2008; 133: 546S-592S.

3. Ogawa S, for the Japanese Circulation Society Joint Working Groups. Guidelines for pharmacotherapy of atrial fibrillation. Circ J 2008; 72(Suppl IV): 1639-1658.

4. Choudhry NK, Soumerai SB, Normand SL, Ross-Degnan D, Laupacis A, Anderson GM. Warfarin prescribing in atrial fibrillation: The impact of physician, patient, and hospital characteristics. Am J Med 2006; 119: 607-615.

5. Go AS, Hylek EM, Borowsky LH, Phillips KA, Selby JV, Singer DE. Warfarin use among ambulatory patients with nonvalvular atrial fibrillation: The anticoagulation and risk factors in atrial fibrillation (ATRIA) study. Ann Intern Med 1999; 131: 927-934.

6. Ansell J, Hirsh J, Hylek E, Jacobson A, Crowther M, Palareti G. Pharmacology and management of the vitamin K antagonists: American College of Chest Physicians Evidence-Based Clinical Practice Guidelines (8th edition). Chest 2008; 133: 160S-198S.

7. Furugohri T, Isobe K, Honda Y, Kamisato-Matsumoto C, Sugiyama $\mathrm{N}$, Nagahara T, et al. DU-176b, a potent and orally active factor Xa inhibitor: In vitro and in vivo pharmacological profiles. J Thromb Haemost 2008; 6: 1542-1549.

8. Matsushima N, Lee F, Sato T, Weiss D, Mendell J. Absolute bioavailability of edoxaban in healthy subjects. AAPS J 2011; 13(Suppl2). http://www.aapsj.org/abstracts/AM_2011/T2362.pdf (accessed April 19, 2012).

9. Ogata K, Mendell-Harary J, Tachibana M, Masumoto H, Oguma T, Kojima M, et al. Clinical safety, tolerability, pharmacokinetics, and 
pharmacodynamics of the novel factor Xa inhibitor edoxaban in healthy volunteers. J Clin Pharmacol 2010; 50: 743-753.

10. Koretsune Y, Inoue H, Kawai Y, Uchiyama S, Yamaguchi T. The oral factor Xa inhibitor DU-176b in Japanese warfarin-naive patients with atrial fibrillation: Results of two phase II open-label, dose-escalation studies. Abstract presented at the 58th Annual Scientific Sessions of the American College of Cardiology; 29-31 March 2009; Orlando, FL, USA

11. Weitz JI, Connolly SJ, Patel I, Salazar D, Rohatagi S, Mendell J, et al. Randomised, parallel-group, multicentre, multinational phase 2 study comparing edoxaban, an oral factor Xa inhibitor, with warfarin for stroke prevention in patients with atrial fibrillation. Thromb Haemost 2010; 104: 633-641.

12. Shinohara Y, Yamaguchi T. Outline of the Japanese guidelines for the management of stroke 2004 and subsequent revision. Int J Stroke 2008; 3: 55-62.

13. Yasaka M, Minematsu K, Yamaguchi T. Optimal intensity of international normalized ratio in warfarin therapy for secondary prevention of stroke in patients with non-valvular atrial fibrillation. Intern Med 2001; 40: $1183-1188$

14. Petersen P, Grind M, Adler J. Ximelagatran versus warfarin for stroke prevention in patients with nonvalvular atrial fibrillation: SPORTIF II: A dose-guiding, tolerability, and safety study. $J \mathrm{Am}$ Coll Cardiol 2003; 41: 1445-1451.

15. Rosendaal FR, Cannegieter SC, van der Meer FJ, Briët E. A method to determine the optimal intensity of oral anticoagulant therapy. Thromb Haemost 1993; 69: 236-239.

16. Lovelock CE, Cordonnier C, Naka H, Al-Shahi Salman R, Sudlow CL; Edinburgh Stroke Study Group, et al. Antithrombotic drug use, cerebral microbleeds, and intracerebral hemorrhage: A systematic review of published and unpublished studies. Stroke 2010; 41: $1222-1228$

17. Lee SH, Ryu WS, Roh JK. Cerebral microbleeds are a risk factor for warfarin-related intracerebral hemorrhage. Neurology 2010; 72: $171-176$.

18. Suzuki S, Yamashita T, Kato T, Fujino T, Sagara K, Sawada H, et al. Incidence of major bleeding complication of warfarin therapy in Japanese patients with atrial fibrillation. Circ $J$ 2007; 71: 761-765.

19. Mak KH, Bhatt DL, Shao M, Hankey GJ, Easton JD, Fox KA, et al. Ethnic variation in adverse cardiovascular outcomes and bleeding complications in the Clopidogrel for High Atherothrombotic Risk and Ischemic Stabilization, Management, and Avoidance (CHARISMA) study. Am Heart J 2009; 157: 658-665.

20. Wang TY, Chen AY, Roe MT, Alexander KP, Newby K, Smith SC, et al. Comparison of baseline characteristics, treatment patterns, and in-hospital outcomes of Asia versus non-Asian white Americans with non-ST-segment elevation acute coronary syndromes from the CRUSADE quality improvement initiative. Am J Cardiol 2007; 100: 391-396.

21. Shen AYJ, Yao JF, Brar SS, Jorgensen MB, Chen W. Racial/ethnic differences in the risk of intracranial hemorrhage among patients with atrial fibrillation. J Am Coll Cardiol 2007; 50: 309-315.

22. Atarashi H, Inoue H, Okumura K, Yamashita T, Kumagai N, Origasa H; J-RHYTHM Registry Investigators. Present status of anticoagulation treatment in Japanese patients with atrial fibrillation: A report from the J-RHYTHM Registry. Circ J 2011; 75: 1328-1333.

23. Vivas D, Olmos C, Vilacosta I. Atrial fibrillation and anticoagulation therapy: Different race, different risk, and different management? Circ J 2011; 75: 1314-1315.

24. Lip GY, Rasmussen LH, Olsson SB, Zetterstrand S, Stahre C, Bylock A, et al. Oral direct thrombin inhibitor AZD0837 for the prevention of stroke and systemic embolism in patients with non-valvular atrial fibrillation: A Phase II study of AZD0837 in patients who are appropriate for but unable or unwilling to take vitamin $\mathrm{K}$ antagonist therapy. Thromb Res 2011; 127: 91-99.

25. Ruff CT, Giugliano RP, Antman EM, Crugnale SE, Bocanegra T, Mercuri M, et al. Evaluation of the novel factor Xa inhibitor edoxaban compared with warfarin in patients with atrial fibrillation: De- sign and rationale for the Effective aNticoaGulation with factor $\mathrm{xA}$ next GEneration in Atrial Fibrillation-Thrombolysis In Myocardial Infarction study 48 (ENGAGE AF-TIMI 48). Am Heart J 2010; 160: $635-641$.

\section{Appendix}

Event Assessment Committee Members

Yasuhiro Hasegawa, St. Marianna University; Toshihiko Iwamoto, Tokyo Medical University; Jun Hatazawa, Osaka University Graduate School of Medicine; Masatoshi Kawana, Tokyo Women's Medical University Aoyama Hospital; Ikuro Maruyama, Graduate School of Medical and Dental Sciences, Kagoshima University.

\section{Data and Safety Monitoring Board Members}

Shinya Goto, Tokai University School of Medicine; Mitsuru Murata, Keio University Hospital; Hideki Origasa, University of Toyama; Makoto Takagi, Tokyo Saiseikai Central Hospital.

Principal Investigators and Study Sites

Masayoshi Ajioka and Shigehisa Mitake, Tosei General Hospital; Teisuke Anzai, National Hospital Organization Hakodate National Hospital; Tetsuo Betsuyaku, National Hospital Organization Hokkaido Medical Center; Shigeru Fujimoto, Nippon Steel Yawata Memorial Hospital; Nobuo Fukuda, National Hospital Organization Zentsuji National Hospital; Yutaka Furukawa, Kobe City Medical Center General Hospital; Kazumasa Harada, Tokyo Metropolitan Geriatric Hospital; Yoshikazu Hiasa, Tokushima Red Cross Hospital; Teruyuki Hirano and Seigo Sugiyama, Kumamoto University Hospital; Naohisa Hosomi, Kagawa University Hospital; Hidekazu Ino, Kanazawa University Hospital; Yasuhiro Ishibashi, Iwate Medical University Hospital; Takao Ishitsuka, Kyushu Rosai Hospital; Kazunori Iwade, National Hospital Organization Yokohama Medical Center; Toshiya Iwasaki, Cardiovascular Hospital of Central Japan; Takamasa Iwasawa, Yokosuka General Hospital Uwamachi; Tohru Izumi, Kitasato University Hospital; Ryo Kataoka, Hokushinkai Megumino Hospital; Takanari Kitazono, Kyushu University Hospital; Youichi Kobayashi, Showa University Hospital; Yoshinori Kobayashi, Nippon Medical School Hospital; Eitaro Kodani, Nippon Medical School Tama Nagayama Hospital; Yukihiro Koretsune, National Hospital Organization Osaka National Hospital; Masahiko Kurabayashi, Gunma University Hospital; Katsumi Kurokawa, Hiroshima City Asa Hospital; Tohru Masuyama, The Hospital of Hyogo College of Medicine; Ban Mihara, Institute of Brain and Blood Vessels Mihara Memorial Hospital; Shinji Miki, Mitsubishi Kyoto Hospital; Hironori Murakami, Keijinkai Teine Keijinkai Hospital; Kunihiko Nagai, TazukeKoufukai Igakukenkyujo Kitano Hospital; Yoshiyuki Nagai, Rinku General Medical Center; Ken Nagata, Research Institute for Brain and Blood Vessels Akita; Junichi Nakagawa, Daishinkai Medical Corporation Ookuma Hospital; Jyoji Nakagawara, Nakamura Memorial Hospital; Toshihiro Nakamura, National Hospital Organization Kyushu Medical Center; Shinsuke Nanto, Kansai Rosai Hospital; Satoshi Ogawa and Norihiro Suzuki, Keio University Hospital; Hiroaki Oguro, Shimane University Hospital; Satoshi Okuda, National Hospital Organization Nagoya Medical Center; Ken Okumura, Hirosaki University School of Medicine \& Hospital; Toshiho Ohtsuki, Hiroshima University Hospital; Toshiyuki Osaka, Shizuoka Saiseikai General Hospital; Keijiro Saku, Fukuoka University Hospital; Taku Sakurada, Sapporo Central Hospital; Tatsuya Sasaki, National Hospital Organization Osaka Minami Medical Center; Yoshihiko Seino, Nippon Medical School Chiba Hokusoh Hospital; Tetsuro Shirai, Tokyo Metropolitan Police Hospital; Takahito Sone, Ogaki Municipal Hospital; Kaoru Sugi, Toho University Ohashi Medical Center; Makoto Suzuki, Ehime Prefectural Central Hospital; Hiroto Takeda, Ohta General Hospital Foundation Ohta Nishinouchi Hospital; Kou Takeda, Kagawa Prefectural Central Hospital; Takashi Takenaka, National Hospital Organization Hokkaido Cancer Center; Masahiro Tsuzuki, Sapporo Junkanki Hospital; Takaaki Yamada, Osaka General Medical Center (Kyuseiki Sogo Iryo Center); Akira Yamashina, Tokyo Medical University Hospital; Takeshi Yamashita, The Cardiovascular Institute Hospital; Hideaki Yoshino, Kyorin University Hospital. 